() Карамова А.Э., Воронцова А.А. ${ }^{*}$, Жилова М.Б., Знаменская Л.Ф., Сайтбурханов Р.Р., Аулова К.М.

Государственный научный центр дерматовенерологии и косметологии

107076, г. Москва, ул. Короленко, д. 3, стр. 6

Сочетание двух злокачественных новообразований - грибовидного микоза (эпидермотропная Т-клеточная лимфома) и меланомы кожи - редкое состояние. В литературе описаны как случаи развития грибовидного микоза у пациентов с первичным диагнозом меланомы кожи, так и выявление меланомы у пациентов с Т-клеточными лимфомами кожи. Дискутабельным остается вопрос о влиянии предшествующей терапии грибовидного микоза на риск возникновения меланомы кожи. В настоящее время мировым сообществом рассматривается возможная патогенетическая взаимосвязь этих двух онкопатологий. Представленные в статье клинические наблюдения развития меланомы кожи у 2 больных грибовидным микозом подчеркивают важность тщательного клинического и дерматоскопического осмотра всех пигментных образований для своевременного выявления злокачественного меланоцитарного новообразования, наличие которого кардинальным образом влияет на дальнейший выбор тактики лечения больных.

Ключевые слова: Т-клеточная лимфома кожи, грибовидный микоз, меланома кожи.

Конфрликт интересов: авторы данной статьи подтвердили отсутствие конфрликта интересов, о котором необходимо сообщить.

Источник фринансирования: рукопись подготовлена (работа/исследования выполнены) и опубликована за счет финнансирования по месту работы авторов.

Согласие пациента: пациенты добровольно подписали информированное согласие на публикацию персональной медицинской информации в обезличенной форме именно в журнале «Вестник дерматологии и венерологии».

Для цитирования: Карамова А.Э., Воронцова А.А., Жилова М.Б., Знаменская Л.Ф., Сайтбурханов Р.Р., Аулова К.М. Меланома у больных грибовидным микозом. Вестник дерматологии и венерологии. 2021;97(6):87-95. doi: https://doi.org/10.25208/vdv1288 


\title{
Welanoma in patients with mycosis fungoides
}

\author{
(C) Arfenya E. Karamova, Anastasiya A. Vorontsova*, Maryanna B. Zhilova, Lyudmila F. Znamenskaya, Rifat R. Saytburkhanov, \\ Kseniya M. Aulova
}

\section{State Research Center of Dermatovenereology and Cosmetology \\ Korolenko str., 3, bldg 6, 107076, Moscow, Russia}

The development of both malignant neoplasms - mycosis fungoides and cutaneous malignant melanoma - is a rare condition; nevertheless, the literature describes both cases of the development of mycosis fungoides in patients with a primary diagnosis of melanoma and the detection of cutaneous malignant melanoma in patients with T-cell lymphomas of the skin. The question of the effect of previous therapy for mycosis fungoides on the risk of cutaneous malignant melanoma remains controversial. Currently, the world community is considering a possible pathogenetic relationship between these two oncopathologies. The clinical observations of the development of cutaneous malignant melanoma in 2 patients with mycosis fungoides presented in the article emphasize the importance of a thorough clinical and dermatoscopic examination of all pigmented formations for the timely detection of malignant melanocytic neoplasms, the presence of which radically affects the further choice of treatment tactics for patients.

Keywords: T-cell lymphoma of the skin, mycosis fungoides, cutaneous malignant melanoma.

Conflict of interest: the authors declare that there are no obvious and potential conflicts of interest associated with the publication of this article.

Source of funding: the work was done through financing at the place of work of the authors.

Patient consent: the patients voluntarily signed an informed consent to the publication of personal medical information in an impersonal form in the journal "Vestnik Dermatologii i Venerologii"

For citation: Karamova AE, Vorontsova AA, Zhilova MB, Znamenskaya LF, Saytburkhanov RR, Aulova KM. Melanoma in patients with mycosis fungoides. Vestnik Dermatologii i Venerologii. 2021;97(6):87-95.

doi: https://doi.org/10.25208/vdv1288 
Актуальность

Меланома кожи - злокачественная опухоль нейроэктодермального происхождения, исходящая из меланоцитов [1]. Согласно отчету ФГБУ «НМИЦ радиологии» Минздрава России о состоянии онкологической помощи населению в Российской Федерации за 2019 г., распространенность меланомы кожи составила 66,9 на 100000 населения, что превышает аналогичный показатель за $2018(61,4)$ и $2017(61,2)$ гг. Обращает на себя внимание снижение процента выявляемости заболевания на III-IV стадии в сравнении с 2009 г. (28,9\%) - данный показатель в 2019 г. составил 17,8\%. Летальность больных меланомой кожи в 2019 г. составила 9,5\% [2].

Грибовидный микоз - первичная эпидермотропная Т-клеточная лиморома кожи, характеризующаяся пролиферацией малых и средних Т-лимфоцитов с церебриформными гиперхромными ядрами [3, 4], на его долю приходится до 65\% регистрируемых случаев Т-клеточных лимфом кожи [5]. В настоящее время в Российской Федерации нет статистических данных о заболеваемости и распространенности Т-клеточных лимфом кожи ввиду отсутствия формы государственного статистического наблюдения с подразделением лимфопролисеративных заболеваний на отдельные нозологические формы [6].

Сочетание данных патологий является редкостью, тем не менее в литературе описаны как случаи развития грибовидного микоза у пациентов с первичным диагнозом меланомы кожи, так и ситуации выявления меланомы у пациентов с Т-клеточными лимфомами кожи, в том числе у пациентов, не получавших ранее ультрафиолетовую терапию и не имевших предрасполагающих фракторов риска развития меланомы [8-11].

В ФГБУ «ГНЦДК» Минздрава России за период с 2018 по 2020 г. под наблюдением находилось 34 больных с грибовидным микозом, у двух на этапе обследования была диагностирована меланома кожи. Приводим собственные клинические наблюдения.

\section{Описание случая}

\section{Клинический случай 1}

Пациент Б., 68 лет, болен с 2016, когда впервые отметил появление пятнистых высыпаний на коже спины, сопровождавшихся выраженным зудом. В КВД по месту жительства установлен диагноз «псориаз» и проведен курс фрототерапии с временным положительным эффектом. В апреле 2019 г. в МОНИКИ им. Владимирского проведено гистологическое исследование, морфологическая картина которого соответствовала грибовидному микозу. Проведено ПЦР-исследование, выявлена моноклональность по генам гамма цепи Т-клеточного рецептора, установлен диагноз грибовидного микоза, бляшечная стадия.

При обращении в ФГБУ «ГНЦДК» Минздрава России кожный патологический процесс носил распространенный характер; высыпания локализовались на коже лица, туловища, верхних и нижних конечностей и были представлены пятнами и бляшками с инфильтрацией разной степени выраженности; окраска высыпаний варьировала от светло-розового до ярко-розового цвета, местами с буроватым и синюшным оттенками, часть высыпаний имела на своей поверхности шелушение (рис. 1). На коже бедер отмечались очаги с признаками фролликулотропизма (см. рис. 1в). На коже левого плеча локализовался отличный от остальных инфильтра- тивно-бляшечный очаг с выраженным экссудативным компонентом (см. рис. 1д), в области щек - множественные мелкие субэпидермальные кисты с желтовато-белым содержимым (см. рис. 1г).

Обращало на себя внимание большое количество себорейных кератом, а также наличие плоских пигментных образований коричневого и темно-коричневого цвета на коже головы и верхней трети туловища (рис. 2). При проведении дерматоскопии пигментных образований в одном из очагов (см. рис. 2б) в иммерсионной среде наблюдалась гетерогенная пигментация по типу псевдосети, представленная сине-серыми точками; пигментация перифолликулярных структур асимметричная, отмечена редукция фолликулярных структур (рис. 3).

Проведена биопсия пигментного образования, при гистологическом исследовании фрагмент опухоли был представлен комплексами и одиночными меланоцитами, распространяющимися вдоль базального слоя эпидермиса, на вышележащие отделы и в сосочковый слой дермы. Клетки округлой и вытянутой формы, со светлой цитоплазмой содержали пигмент. Отмечалось распространение опухолевых клеток по ходу придатков кожи (эпителия волосяного фолликула). Опухолевые клетки с выраженным полиморфизмом, низкой мито-

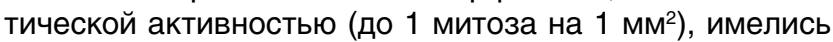
очаговые отложения глыбчатого буроватого внеклеточного пигмента, слабо и умеренно выраженная перифокальная лимфоидная инфильтрация в дерме. Признаков изъязвления, лимфоваскулярной и периневральной инвазии в пределах просмотренного материала не выявлено, имелись признаки солнечного эластоза в дерме. Морфологическая картина соответствовала лентиго-меланоме кожи (рис. 4).

Проведено УЗИ периферических лимфатических узлов, выявлена лимфаденопатия: подчелюстные, подмышечные, паховые и бедренные лимфатические узлы увеличены от 1,8 до 3,5 см в диаметре, плотноэластической консистенции, не спаяны с окружающими тканями, с сохраненной эхоструктурой, гиперваскулярные.

Поставлен диагноз: Т-клеточная лимфома кожи. Грибовидный микоз, стадия ІІА; лентиго-меланома.

Учитывая тяжесть кожного патологического процесса и наличие злокачественного пигментного новообразования, пациенту был назначен метотрексат в дозе 30 мг 1 раз в неделю и рекомендована консультация онколога для решения вопроса о дальнейшей тактике лечения.

Со слов пациента, в ФГБУ «НМИЦ радиологии» Минздрава России проведено повторное исследование готового гистологического препарата, диагноз лентиго-меланомы был подтвержден, произведено иссечение образования в пределах здоровых тканей (рис. 5в). Дополнительная противоопухолевя терапия не назначалась.

На фоне терапии метатрексатом в дозе 30 мг еженедельно за 8 месяцев удалось достичь выраженной положительной динамики в виде регресса большинства высыпаний (см. рис. 5).

\section{Клинический случай 2}

Пациентка С., 29 лет, в сентябре 2020 г. обратилась в ФГБУ «ГНЦДК» Минздрава России с жалобами на высыпания на коже живота и нижних конечностей. 


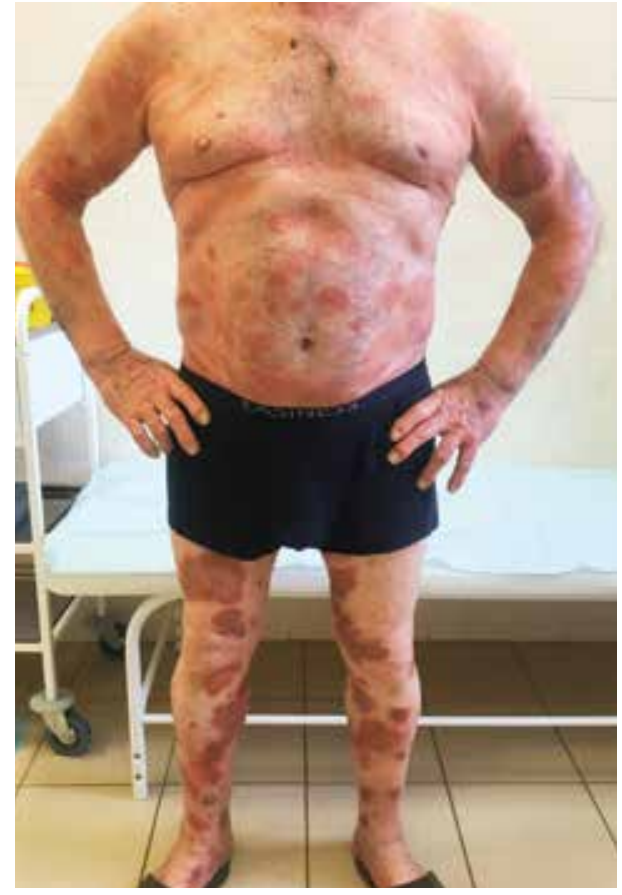

$a$

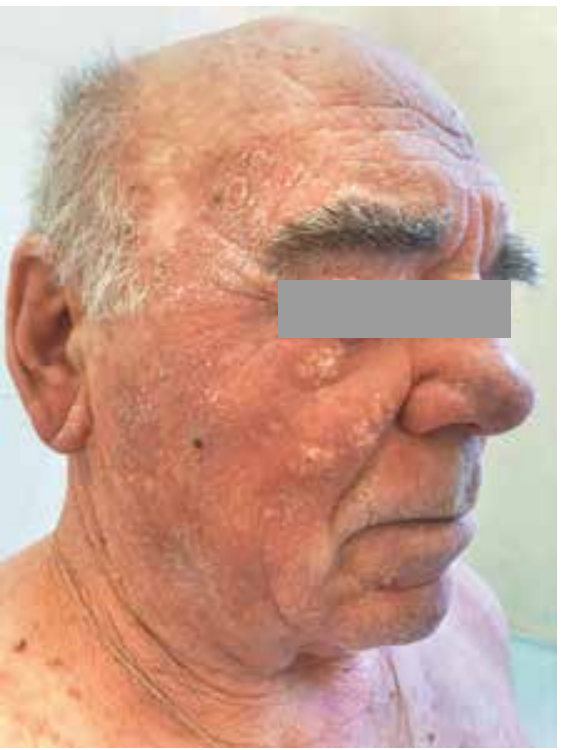

$\Gamma$

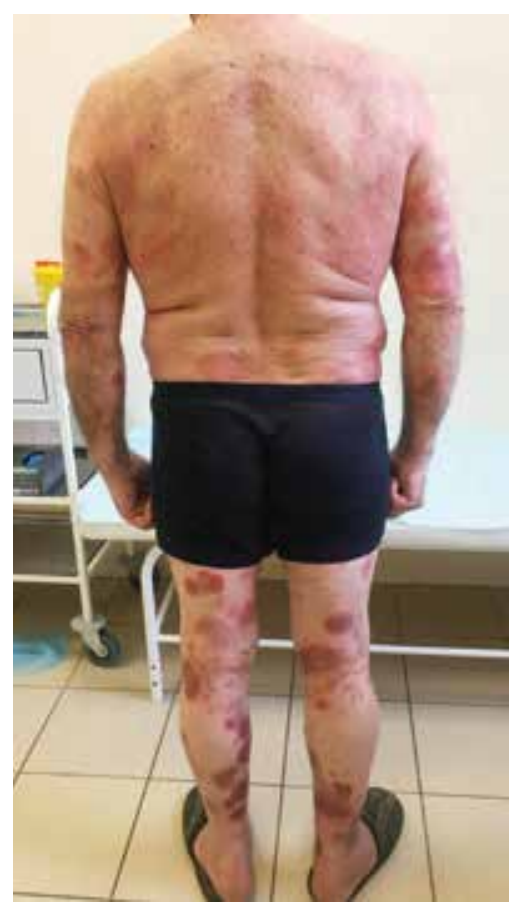

б

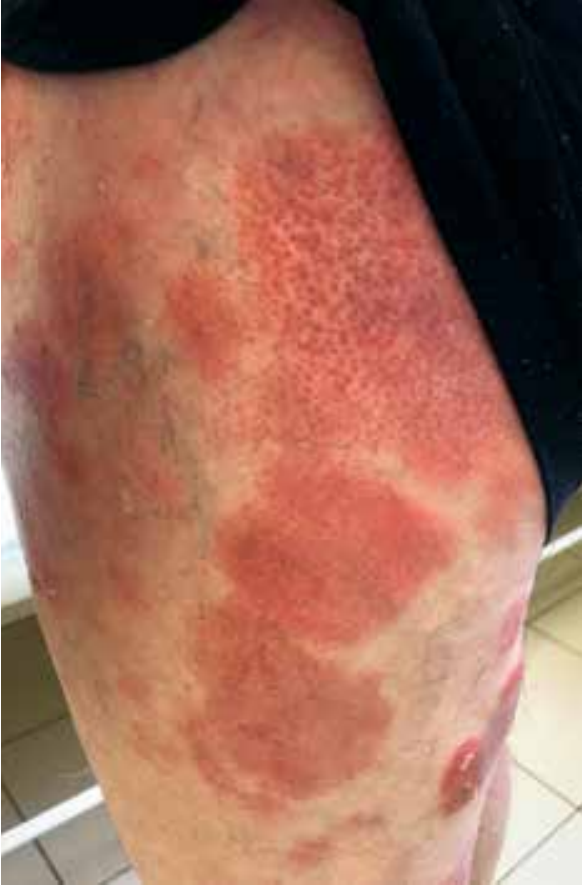

$B$

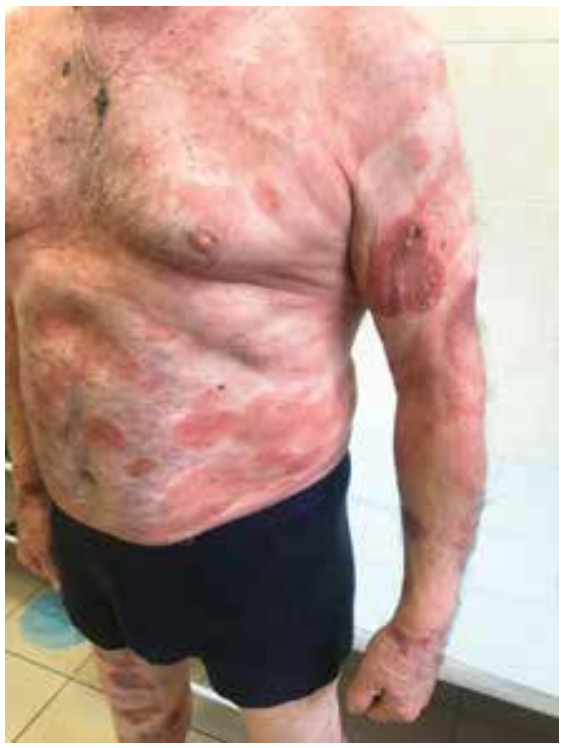

Д

\footnotetext{
Рис. 1. Клиническая картина пациента Б. при обращении: (а, б) — распространенные пятнистые и инфильтративно-бляшечные элементы; (в) - очаг с признаками фолликулотропизма на коже левого бедра; $(r)$ - множественные мелкие субэпидермальные кисты с желтовато-белым содержимым на коже правой щеки; (д) - инфильтративно-бляшечный очаг с выраженными экссудативным компонентом на коже левого плеча

Fig. 1. Clinical findings in patient B.: $(a, b)$ - extensive patches and plaques; $(c)$ — Folliculotropic lesions on the left thigh; (d) — multiple subepidermal cystis with yellowwhite contents on the right cheek; $(e)$ - plaque with exudation on the left shoulder
}

Со слов пациентки, в 2005 г. отметила появление единичного шелушащегося розового пятна на коже задней поверхности левого бедра без субъективных ощущений. С 2005 по 2015 г. отмечала перифрерический рост пятна и появление аналогичных высыпаний на коже ягодиц и нижних конечностей, в связи с чем с 2015 г. неоднократно обращалась в КВД по месту жительства и в частные клиники, где устанавлива- лись диагнозы «атопический дерматит», «псориаз» и назначалась соответствующая терапия с временным положительным эфффектом. В 2019 г. при обращении в МОНИКИ им. Владимирского проведена диагностическая биопсия кожи с последующим гистологическим исследованием, заключение которого: «Гистологические изменения могут наблюдаться при грибовидном микозе в стадии пятна». В апре- 


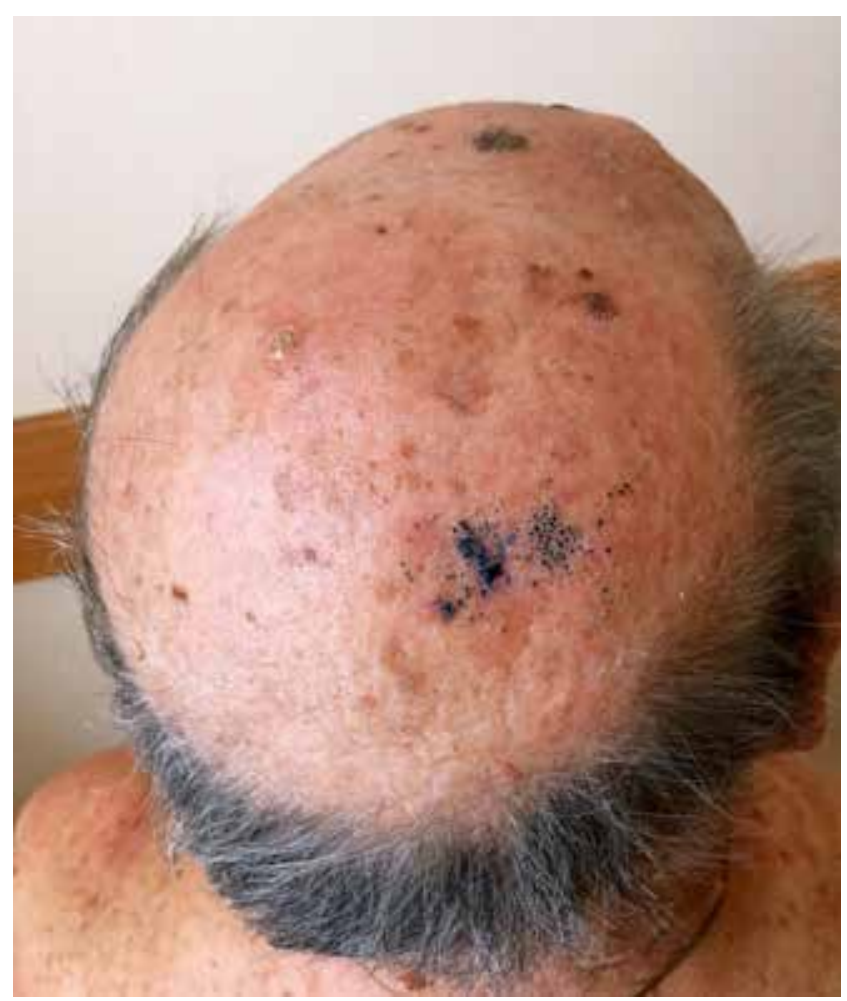

a

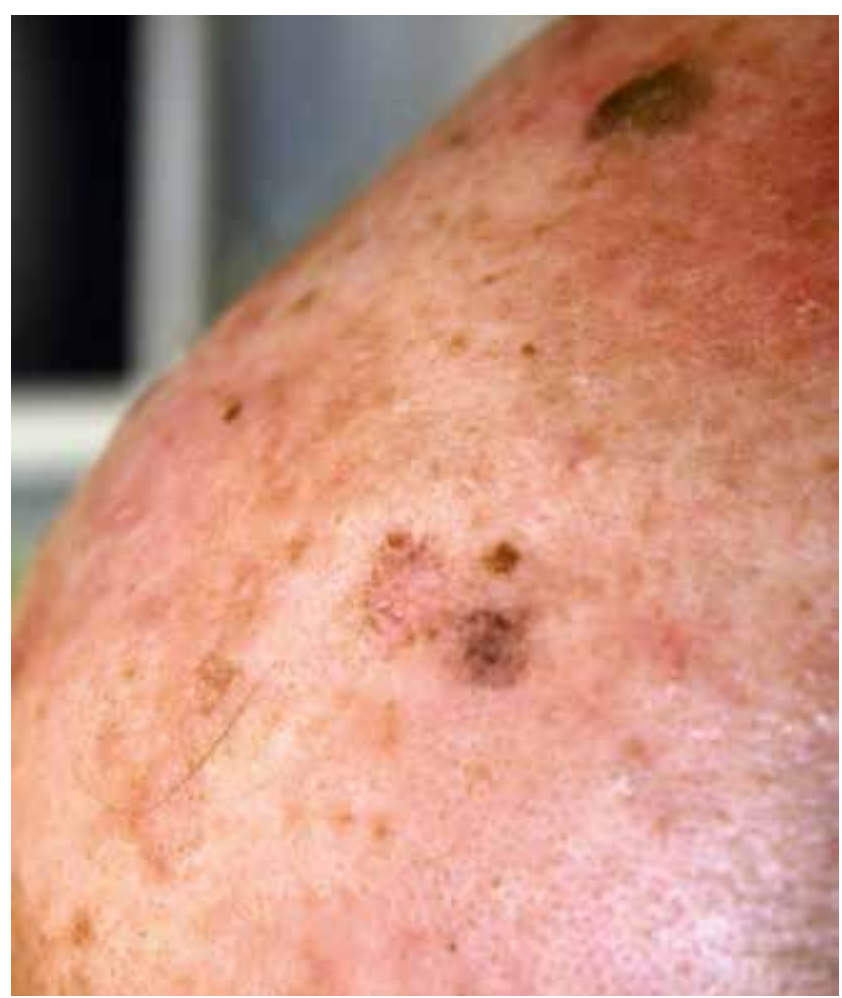

Рис. 2. Себорейные кератомы и пигментные образования у пациента Б. на коже волосистой части головы при обращении

Fig. 2. Seborrheic keratosis and pigmented lesions on the scalp in patient B.

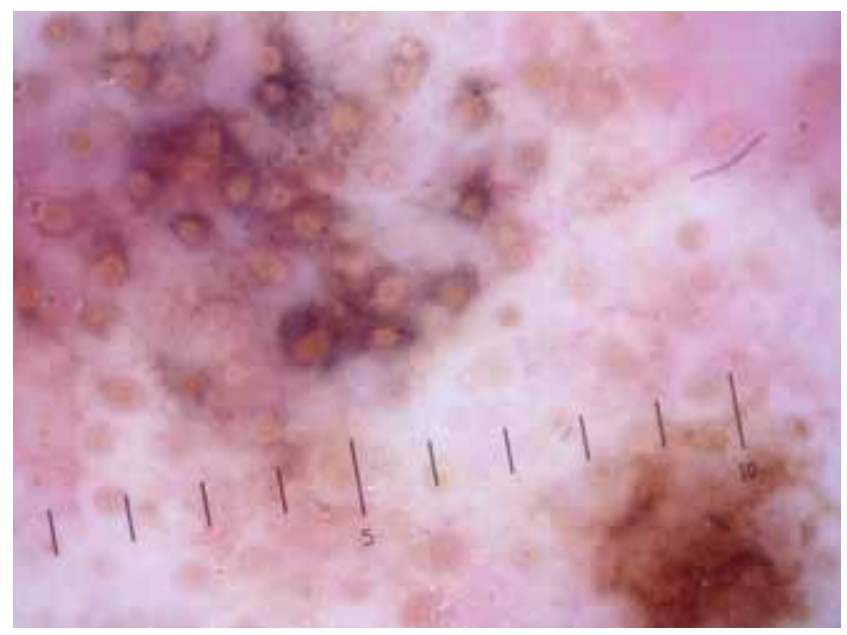

Рис. 3. Дерматоскопическая картина пигментного образования на коже волосистой части головы у пациента Б. представлена гетерогенной пигментацией по типу псевдосети сине-серыми точками, пигментация перифолликулярных структур ассиметричная, наблюдается редукция фолликулярных структур

Fig. 3. Dermascopy of pigmented lesion on the scalp in patient B. There are heterogenic pigmentation by pseudonetwork type (blue-grey spots), asymmetric pigmentation of perifollicular structure, reduction of follicular structure in the dermascopic picture

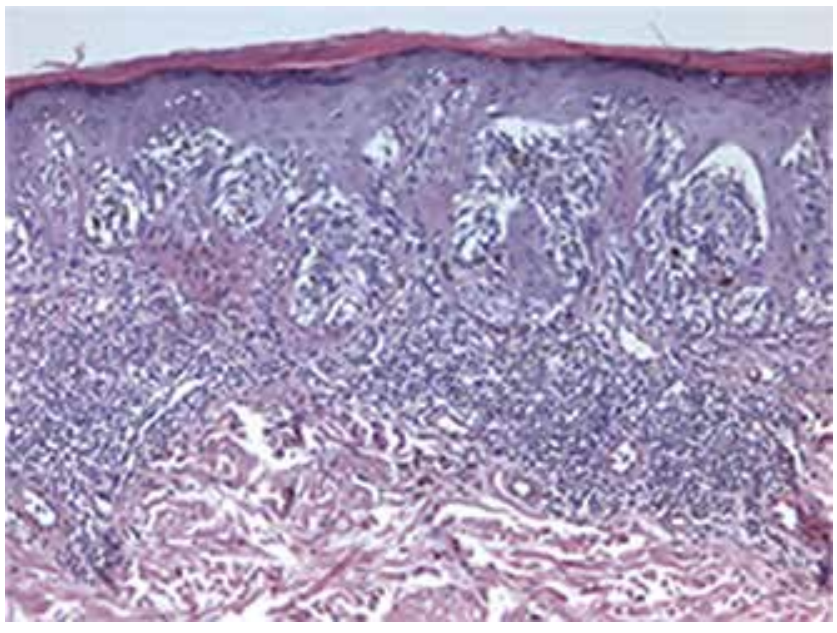

Рис. 4. Морфологическая картина пигментного новообразования у пациента Б. Увеличение $\times 200$ — клетки округлой и вытянутой формы, со светлой цитоплазмой, содержат пигмент; опухолевые клетки с выраженным полиморфизмом, с низкой митотической активностью (до 1 митоза на 1 мм²), имеются очаговые отложения глыбчатого буроватого внеклеточного пигмента; признаков изъязвления, лимфоваскулярной и периневральной инвазии в пределах просмотренного материала не выявлено; в дерме признаки солнечного эластоза

Fig. 4. The morphological picture of a melanocytic neoplasm in patient $B$ Magnification $\times 200$ - cells of a round and elongated shape, with a light cytoplasm, contain pigment; tumor cells with pronounced polymorphism, with low mitotic activity (up to 1 mitosis per $1 \mathrm{~mm}^{2}$ ), there are focal deposits of lumpy brownish extracellular pigment; signs of ulceration, lymphovascular and perineural invasion were not identified within the examined material; in the dermis there are signs of solar elastosis 


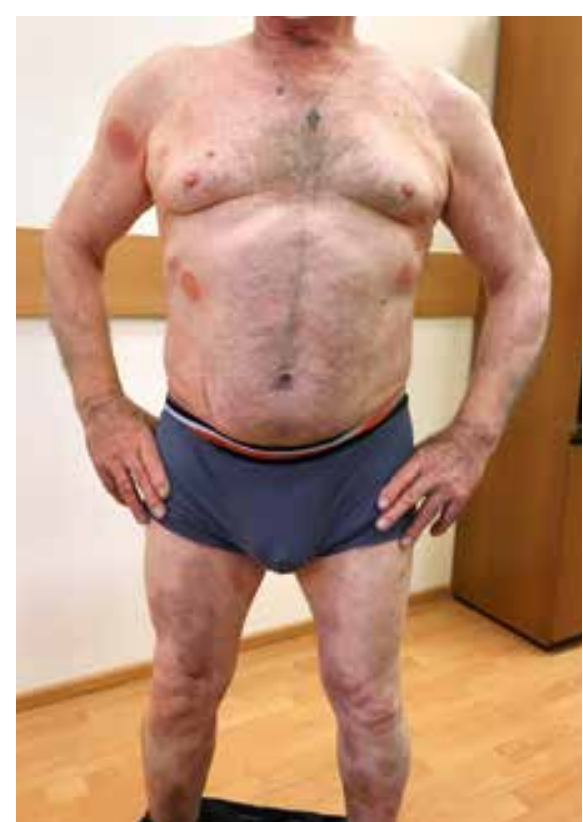

a

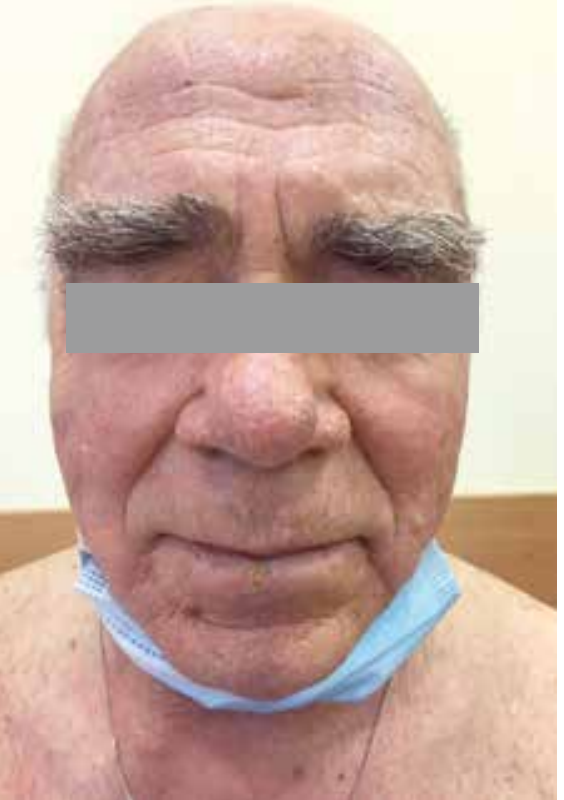

$\sigma$

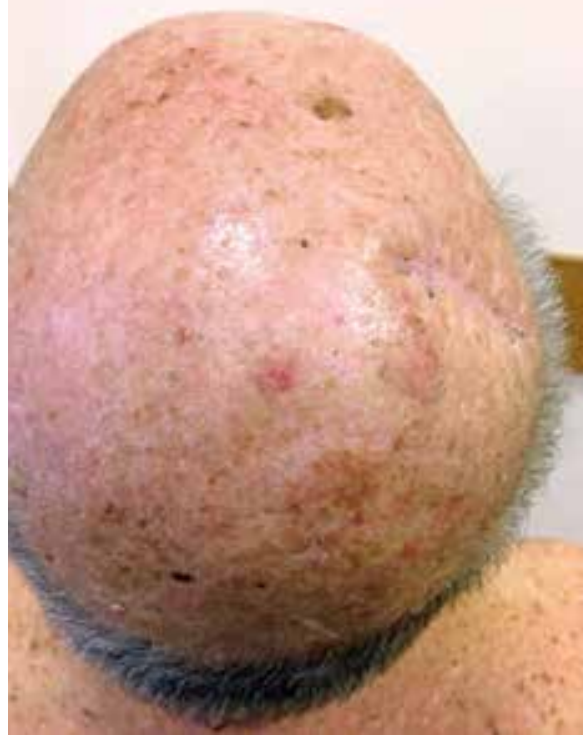

$B$

Рис. 5. Клиническая картина пациента Б. после 8 месяцев терапии метотрексатом в дозе 30 мг

Fig. 5. Clinical findings in patient $B$. after treatment of methotrexate $30 \mathrm{mg}$ during 8 months

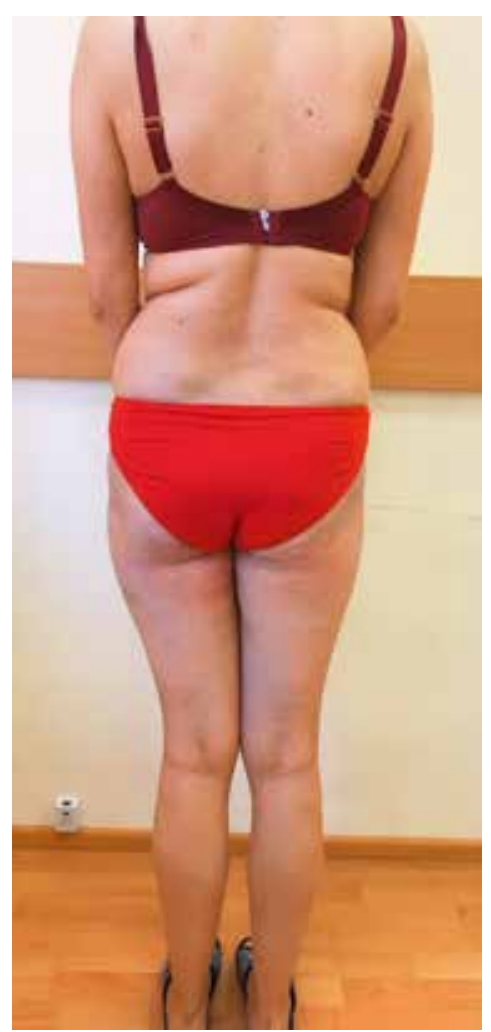

a

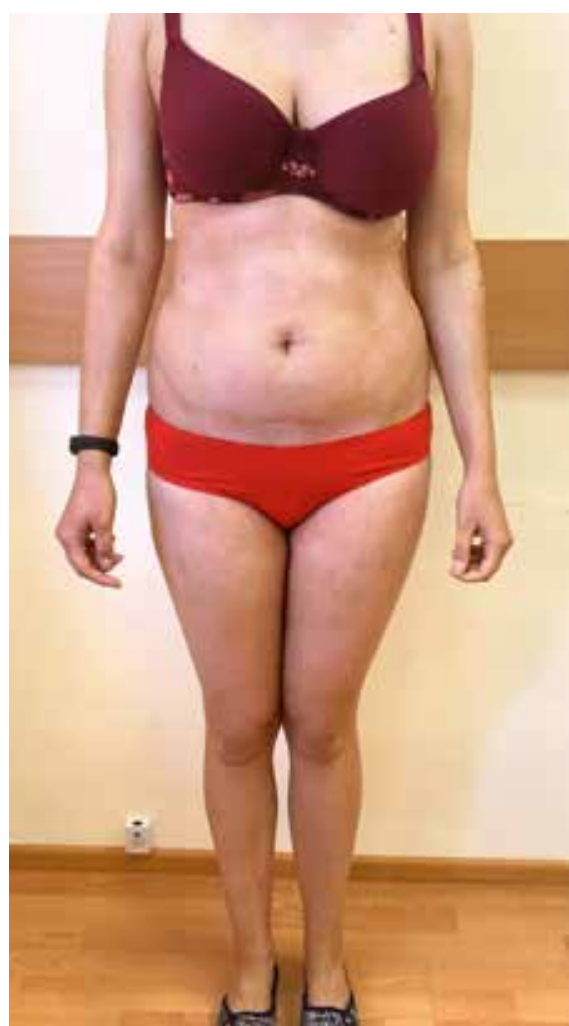

$\sigma$

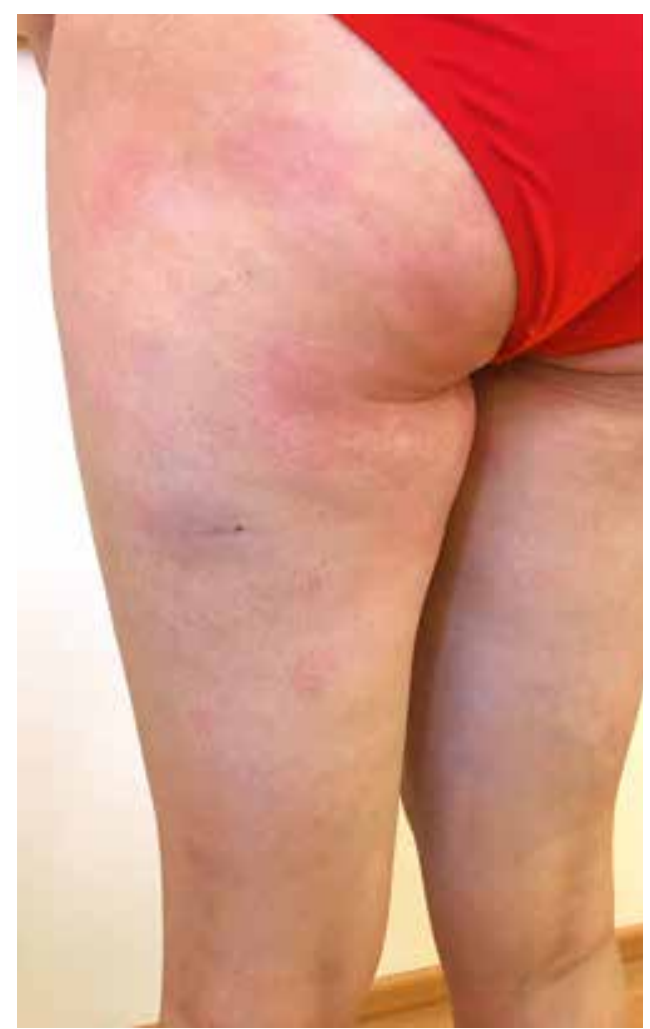

$B$

Рис. 6. Клиническая картина пациентки С. при поступлении: (а, б) — множественные пятнистые элементы на коже живота, передней и задней поверхности обоих бедер;
(в) - светло-розовые и розовые пятнистые высыпания на коже ягодичной области с переходом на кожу бедра
Fig. 6. Clinical findings in patient C.: $(a, b)$ - multiple patches on the abdomen and thighs; $(c)$ - light rose-colored patches on the gluteal regions extending to thighs 


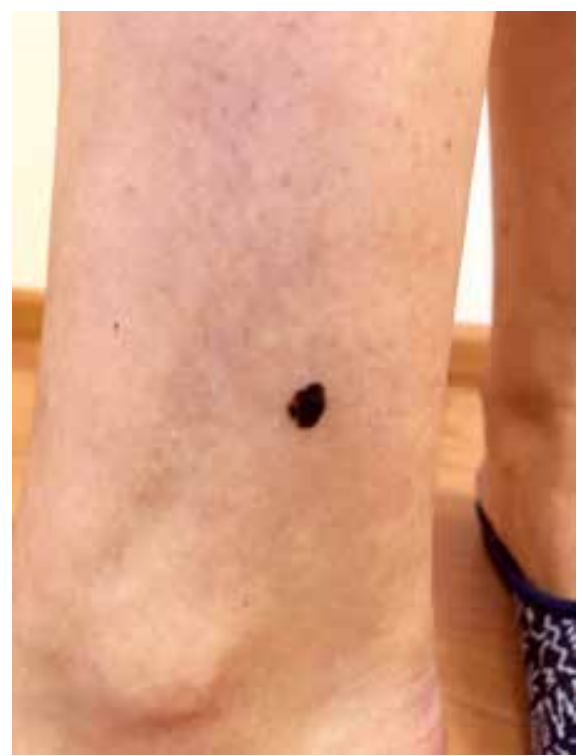

Рис. 7. Пигментное новообразование неправильной формы, темно-коричневого, почти черного цвета на коже правой голени у пациентки С. при поступлении

Fig. 7. Pigmented lesion of irregular shape and dark-brown color on the right shin in patient $\mathrm{C}$.

ле 2020 г. в ФГБУ «НМИЦ гематологии» Минздрава России проведено повторное исследование готовых гистологических препаратов, ПЦР-исследование и иммуногистохимическое исследование на срезах готовых парафиновых блоков. Учитывая выявленные моноклональность по генам бета-цепи Т-клеточного рецептора, экспрессию лимфоцитами инфильтратов маркеров CD3, CD4, CD8 (соотношение CD4 к CD8 3:1) и отсутствие экспрессии CD7 на части лимфоцитов, установлен диагноз грибовидного микоза в стадии пятна; рекомендовано динамическое наблюдение и проведение повторного гистологического исследования в случае появления очага с выраженной инфильтрацией.

Площадь поражения при поступлении в ФГБУ «ГНЦДК» Минздрава России составляла не более 15\%, клиническая картина была представлена исключительно пятнистыми элементами, которые локализовались на коже живота, нижней трети спины, ягодичной области и на коже обоих бедер. Преобладали высыпания светло-розового и розового цвета, однако на коже живота часть очагов имели признаки депигментации (рис. 6б); единичные очаги были с незначительным шелушением (см. рис. 6).

При осмотре привлекло внимание плоское пигментное новообразование неправильной формы, темнокоричневого, почти черного цвета на коже внутренней поверхности правой голени (рис. 7). При дерматоскопии очага в иммерсионной среде наблюдались асимметрия пигментации и структуры, нерегулярно расположенные псевдоподии и радиальные линии (рис. 8). Установлен предварительный диагноз «меланома кожи?». Для уточнения диагноза пациентка направлена на консультацию к врачу-онкологу по месту жительства. В ГБУЗ «Московский областной онкологический диспансер» проведено широкое иссечение пигментного образования

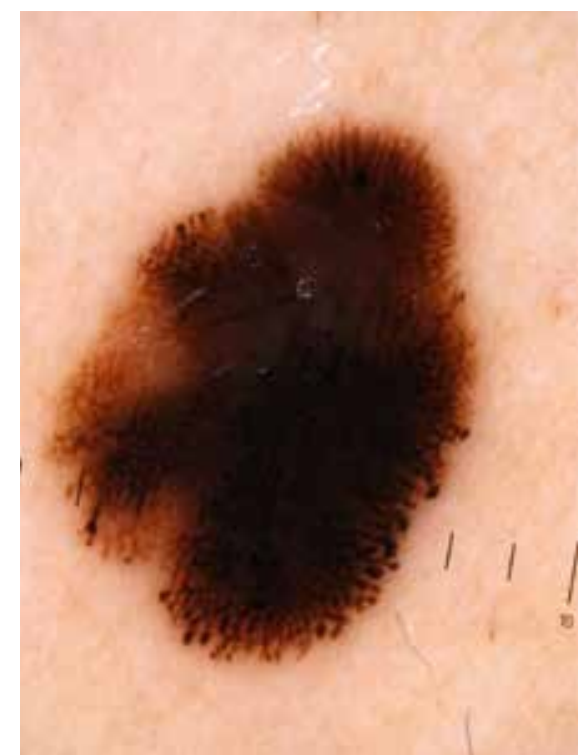

Рис. 8. Дерматоскопическая картина пигментного образования на коже правой голени у пациентки С. — наблюдаются асимметрия пигментации и структуры, нерегулярно расположенные псевдоподии и радиальные линии Fig. 8. Dermascopy of pigmented lesion on the right shin in patient $C$. There are asymmetry of pigmentation and structure, irregularly spaced pseudopodia and radial lines in the dermascopic picture

на коже правой голени с реконструктивно-пластическим компонентом. При гистологическом исследовании послеоперационного материала выявлена меланома in situ. Лимфоцитарная инфильтрация слабо выражена, изъязвлений нет. Митотический индекс $0 \mathrm{Fm}$ на 1 мм². Края резекции с запасом здоровых тканей.

Проведены УЗИ органов брюшной полости, малого таза и молочных желез, а также рентгенография органов грудной клетки и дуплексное сканирование сосудов нижних конечностей. Согласно полученным результатам установлен диагноз «меланома кожи правой голени pTisNOMO 0 st» (атипическая меланоцитарная гиперплазия, неинвазивная меланома - І уровень по Clark). Показания для назначения дополнительной противоопухолевой терапии отсутствовали.

Учитывая диагностированную меланому кожи, раннюю стадию (IB) грибовидного микоза, отсутствие предшествующей терапии и наличие пятнистых элементов, в настоящее время избрана тактика терапии топическими глюкокортикостероидами высокой степени активности.

\section{Обсуждение}

Одновременное выявление грибовидного микоза и меланомы кожи позволяет наряду с фактором случайности предположить наличие общих патогенетических путей, возможный риск сочетанного развития двух заболеваний, а также влияние проводимой терапии грибовидного микоза на риск развития меланомы кожи.

J.A. Pielop и соавт. (2003 г.) приводят данные о развитии меланомы кожи у 6 из 250 больных грибовидным микозом [8]. Интересно, что у 4 пациентов диагноз меланомы предшествовал развитию грибовидного микоза; авторами было подсчитано, что распространенность меланомы кожи в группе больных грибовидным микозом $(2,4 \%)$ превышает аналогичный показатель $(0,2 \%)$ в целом к общей популяции США [8]. 
Учитывая широкое применение ультрафиолетового излучения в лечении больных грибовидным микозом, а также лучевой терапии, методов, оказывающих иммуносупрессивное действие и обладающих потенциальным канцерогенным эффректом, активно ведется дискуссия о влиянии предшествующей терапии грибовидного микоза на риск возникновения меланомы кожи.

Согласно опубликованным наблюдениям A.G. Licata и соавт. (1995 г.), из 164 пациентов с Т-клеточной лимфомой кожи развитие меланомы было зарегистрировано у 6 больных. Во всех случаях авторы связывают развитие меланомы с предшествующей тотальной лучевой терапией, а также с применением ранее ПУВА-терапии в анамнезе у 3 больных и мехлорэтамина (азотистый иприт) у 2 больных [9]. A.V. Evans и соавт. (2004 г.) публикуют данные о 285 больных грибовидным микозом, из которых у 6 была диагностирована меланома кожи, по мнению авторов, у 4 больных развитие меланомы не было связано с предшествующей терапией грибовидного микоза [10].

В 2020 г. опубликованы результаты сравнительного исследования риска развития меланомы кожи у пациентов с псориазом и грибовидным микозом в сравнении с общей популяцией в Израиле [11]. В исследование были включены данные о 982 больных с грибовидным микозом и 3165 больных с псориазом. Меланома кожи была диагностирована у $47(4,8 \%)$ пациентов с грибовидным микозом и у $23(0,7 \%)$ с псориазом. Примерно в $60 \%$ случаев диагноз грибовидного микоза или псориаза предшествовали развитию меланомы кожи. Коэффрициент заболеваемости меланомой кожи в группе грибовидного микоза в сравнении с общей популяцией составил 17,5 ( $p<0,0001)$ и во много раз превышал аналогичный показатель в группе псориаза - 2,2 $(p=0,148)$. Принимая во внимание широкое использование фототерапии для лечения обоих заболеваний, авторы проанализировали информацию о проводимой ранее терапии; из 3165 больных псориазом фрототерапию ранее получал 1531 (48,6\%) больной, большинству из которых применялась NB-UVB, среди 982 больных грибовидным микозом 537 (53,7\%) не получали ранее фототерапию, из которых у 10 в процессе наблюдения развилась меланома кожи. Основываясь на полученных данных, авторы делают вывод об отсутствии взаимосвязи между проводимой ранее ультрафиолетовой терапией больным грибовидным микозом и риском развития меланомы [11]. Развитию грибовидного микоза у больных меланомой кожи, по мнению ряда исследователей, могут способствовать схожие молекулярногенетические звенья патогенеза - общие ассоциации гистосовместимости аллели локусного антигена (HLA), HLA-DR5 и DQB1 * 03 [12, 13], а также обнаруженные мутации в гене $C D K N 2 A$, кодирующем белок-супрессор p16, при том и другом заболеваниях $[8,14,15]$. Напротив, развитие меланомы у больных грибовидным микозом можно объяснить развитием иммунодесицита (общепризнанный фактор риска меланомы) как при прогрессировании заболевания со смещением цитокинового профиля в сторону Th2-френотипа, так и в случае применения методов терапии с иммуносупрессивным эфрфректом [8, 16]. G. Bar-Sela и соавт. (2015 г.) наблюдали регресс грибовидного микоза у больного после терапии ипилимумабом (моноклональное антитело, связывающее антиген CTLA-4) по поводу меланомы, в связи с чем авторы предполагают, что в основе двух онкологических заболеваний, возможно, лежит иммунологический путь, опосредованный CTLA-4 [17]. В описанных выше случаях диагноз ГМ предшествовал выявлению меланомы. В первом случае пациент получил один курс ПУВА-терапии, однако данный фракт недостаточен для рассмотрения в качестве провоцирующего. Выявление меланомы повлияло на выбор тактики ведения пациентов в пользу отказа от методов фототерапии.

\section{Заключение}

От врача-дерматовенеролога требуется проведение тщательного клинического и дерматоскопического осмотра всех пигментных образований у пациента с грибовидным микозом для своевременного выявления злокачественного меланоцитарного новообразования, наличие которого кардинальным образом влияет на выбор метода терапии.

\section{Литература/References}

1. Алиев М.Д., Гафртон Г.И., Демидов Л.В., Новик А.В., Орлова К.В., и др. Клинические рекомендации: Меланома кожи и слизистых оболочек. Год утверждения: 2019. Одобрено НПС Минздрава PФ. ID: KP546/2 [Aliev MD, Gafton Gl, Demidov LV, Novik AV, Orlova $\mathrm{KV}$, et al. Klinicheskie rekomendatsii: Melanoma kozhi i slizistykh obolochek. God utverzhdeniya: 2019. Odobreno NPS Minzdrava RF. ID:KR546/2 (In Russ.)]

2. Каприн А.Д., Старинский В.В., Шахзадова А.О., ред. Состояние онкологической помощи населению России в 2019 году. М.: МНИОИ им. П.А. Герцена — филиал ФГБУ «НМИЦ радиологии» Минздрава России, 2020 [Kaprin AD, Starinskiy WV, Shakhzadova A0, editors. Sostoyanie onkologicheskoy pomoshchi naseleniyu Rossii v 2019 godu. Moscow: MNIOI im. P.A. Gertsena - filial FGBU "NMITs radiologii" Minzdrava Rossii, 2020 (In Russ.)]
3. Поддубная И.В., Савченко В.Г., ред. Российские клинические рекомендации по диагностике и лечению лимфопролисреративных заболеваний. 2016 [Poddubnaya IV, Savchenko VG, editors. Rossiyskie klinicheskie rekomendatsii po diagnostike i lecheniyu limfoproliferativnykh zabolevaniy. 2016 (In Russ.)]

4. Федеральные клинические рекомендации. Дерматовенерология. 2015: Болезни кожи. Инсрекции, передаваемые половым путем. 5-е изд., перераб. и доп. Москва: Деловой экспресс; 2016 [Federal'nye klinicheskie rekomendatsii. Dermatovenerologiya 2015: Bolezni kozhi. Infektsii, peredavaemye polovym putem. - 5-e izd., pererab. i dop. Moscow. Delovoy ekspress; 2016 (In Russ.)]

5. Willemze R, Jaffe ES, Burg G, Cerroni L, Berti E, Swerdlow SH, et al. WHO-EORTC classification for cutaneous lymphomas. Blood. 2005;105(10):3768-3785. doi: 10.1182/blood-2004-09-3502 
6. Виноградова Ю.Е., Зингерман Б.В. Нозологические формы и выживаемость пациентов с Т- и НК-клеточными лимфатическими опухолями, наблюдающихся в ГНЦ в течение 10 лет. Клиническая онкогематология, Фундаментальные исследования и клиническая практика 2011;4(3)201-212 [Vinogradova YuE, Zingerman BV. Nozologicheskie formy i vyzhivaemost' patsientov s T- i NK-kletochnymi limfa- ticheskimi opukholyami, nablyudayushchikhsya v GNTs v techenie 10 let. Klinicheskaya onkogematologiya, Fundamental'nye issledovaniya i klinicheskaya praktika 2011;4(3)201-212 (In Russ.)]

7. Pielop JA, Brownell I, Duvic M. Mycosis fungoides associated with malignant melanoma and dysplastic nevus syndrome. Int J Dermatol. 2003;42(2):116-22. doi: 10.1046/j.1365-4362.2003.01697.x

8. Licata AG, Wilson LD, Braverman IM, Feldman AM, Kacinski BM. Malignant melanoma and other second cutaneous malignancies in cutaneous T-cell lymphoma: the influence of additional therapy after total skin electron beam radiation. Arch Dermatol 1995;131:432-435.

9. Evans AV, Scarisbrick JJ, Child FJ, Acland KM, Whittaker SJ, RussellJones $R$. Cutaneous malignant melanoma in association with mycosis fungoides. J Am Acad Dermatol. 2004;50(5):701-705. doi: 10.1016/j.jaad.2003.11.054

10. Sherman S, Kremer N, Dalal A, Solomon-Cohen E, Berkovich E, Noyman Y, Ben-Lassan M, Levi A, Pavlovsky L, Prag Naveh H, Hodak E,
Amitay-Laish I. Melanoma Risk is Increased in Patients with Mycosis Fungoides Compared with Patients with Psoriasis and the General Population. Acta Derm Venereol. 2020;100(19):adv00346. doi: 10.2340/00015555-3704

11. Hodak E, Lapidoth M, Kohn K, David M, Brautbar B, Kfir K, et al. Mycosis fungoides: HLA class II associations among Ashkenazi and nonAshkenazi Jewish patients. Br J Dermatol 2001;145:974-980.

12. Jackow CM, McHam JB, Friss A, Alvear J, Reveille JR, Duvic M. HLA-DR5 and DQB1*03 class II alleles are associated with cutaneous T-cell Iymphoma. J Invest Dermatol 1996;107:373-376.

13. Aoude LG, Wadt KA, Pritchard AL, Hayward NK. Genetics of familial melanoma: 20 years after CDKN2A. Pigment Cell Melanoma Res 2015;28:148-160.

14. Navas IC, Ortiz-Romero PL, Villuendas R, Martínez P, García C, Gómez $E$, et al. p16INK4a gene alterations are frequent in lesions of mycosis fungoides. Am J Pathol 2000;156:1565-1572.

15. Olsen CM, Knight LL, Green AC. Risk of melanoma in people with HIV/AIDS in the pre- and post-HAART eras: a systematic review and metaanalysis of cohort studies. PLoS One 2014;9:e95096.

doi: 10.1371/journal.pone.0095096

16. Bar-Sela G, Bergman R. Complete regression of mycosis fungoides after ipilimumab therapy for advanced melanoma. JAAD Case Rep 2015;1:99-100.

Участие авторов: все авторы несут ответственность за содержание и целостность всей статьи. Концепция, дизайн, окончательное одобрение рукописи - А.Э. Карамова; написание статьи, анализ полученных результатов - А.А. Воронцова; анализ полученных результатов, редактирование - Л.Ф. Знаменская, М.Б. Жилова, Р.Р. Сайтбурханов; анализ литературных данных — К.М. Аулова.

Authors' participation: all authors: approval of the final version of the article, responsibility for the integrity of all parts of the article. Concept and design of the study, final approval — Arfenya E. Karamova; text writing, collection and processing of material — Anastasiia A. Vorontsova; collection and processing of material, editing — Lyudmila F. Znamenskaya, Maryanna B. Zhilova, Rifat R. Saytburkhanov; literature data analysis - Kseniya M. Aulova.

\section{Информация об авторах}

*Воронцова Анастасия Александровна - младший научный сотрудник; адрес: Россия, 107076, г. Москва, ул. Короленко, д. 3, стр. 6; ORCID iD: http://orcid.org/0000-0002-3129-0050; eLibrary SPIN: 8334-2890; e-mail: vorontsova@cnikvi.ru

Карамова Арфеня Эдуардовна - к.м.H.; ORCID iD: https://orcid.org/0000-0003-3805-8489; eLibrary SPIN: 3604-6491; e-mail: karamova@cnikvi.ru

Жилова Марьянна Борисовна - д.м.н.; eLibrary SPIN: 8930-4073; e-mail: zhilova@cnikvi.ru

Знаменская Людмила Федоровна - д.м.н.; ORCID iD: https://orcid.org/0000-0002-2553-0484; eLibrary SPIN: 9552-7850; e-mail: znaml@cnikvi.ru

Сайтбурханов Рифат Рафаилевич — врач-дерматовенеролог; ORCID iD: https://orcid.org/0000-0001-6132-5632; eLibrary SPIN: 1149-2097, e-mail: rifat03@yandex.ru

Аулова Ксения Максимовна — ORCID iD: http://orcid.org/ 0000-0002-2924-3036; e-mail: kseniabigsmile@mail.ru

\section{Information about the authors}

*Anastasiya A. Vorontsova - research associate; address: 3 bldg 6, Korolenko street, 107076, Moscow, Russia; ORCID iD: http://orcid.org/0000-0002-3129-0050; eLibrarySPIN: 8334-2890; e-mail: vorontsova@cnikvi.ru

Arfenya E. Karamova - MD, Cand. Sci. (Med.); ORCID iD: https://orcid.org/0000-0003-3805-8489; eLibrary SPIN: 3604-6491; e-mail: karamova@cnikvi.ru

Maryanna B. Zhilova — MD, Dr. Sci. (Med.); eLibrary SPIN: 8930-4073; e-mail: zhilova@cnikvi.ru

Lyudmila F. Znamenskaya — MD, Dr. Sci. (Med.); ORCID iD: https://orcid.org/0000-0002-2553-0484; eLibrary SPIN: 9552-7850; e-mail: znaml@cnikvi.ru

Rifat R. Saytburkhanov — dermatovenereologist; ORCID iD: https://orcid.org/0000-0001-6132-5632; eLibrary SPIN: 1149-2097; e-mail: rifat03@yandex.ru

Kseniya M. Aulova — ORCID iD: http://orcid.org/ 0000-0002-2924-3036; e-mail: seniabigsmile@mail.ru

Статья поступила в редакцию: 15.10 .2021

Принята к публикации: 01.11.2021

Дата публикации: 15.12 .2021
Submitted: 15.10 .2021

Accepted: 01.11.2021

Published: 15.12 .2021 